Proceedings of the International Conference in Dubrovnik, 15-16 October 2015

\title{
INTERACTION DIAGRAMS AXIAL FORCE-BENDING MOMENT FOR FIRE EXPOSED STEEL-CONCRETE COMPOSITE SECTIONS
}

\author{
Milivoje Milanovic ${ }^{\mathrm{a}}$, Meri Cvetkovska ${ }^{\mathrm{b}}$ \\ ${ }^{a}$ State University of Novi Pazar, Department of Technical Sciences, Novi Pazar, Serbia \\ ${ }^{\mathrm{b}}$ Ss. Cyril and Methodius University, Faculty of Civil Engineering, Skopje, Macedonia
}

\begin{abstract}
The bearing capacity of the column cross section can be determined from the interaction diagram moment-axial force $(\mathrm{M}-\mathrm{N})$. Fire induced temperatures cause reduction of the load-bearing characteristics of the constitutive materials, steel and concrete, and this effect directly reflects on the reduction of the axial force and the bending moment that could be accepted by the column cross section, respectively the interaction diagram of the column cross section is changed. The load bearing capacity of the steel-concrete composite columns exposed to fire from all four sides and loaded by axial force and uni-axial or bi-axial bending moments, was estimated on the basis of the changes in the interaction diagrams moment-axial force amd the results are presented in this paper. Different types of composite columns made of totally or partially encased steel sections, or concrete filled hollow sections were analyzed and a detailed discussion on the effects of the shape of the cross section and the cross sectional dimensions are presented.
\end{abstract}

Keywords: composite column, temperature, heat transfer, fire resistance, interaction diagrams

\section{INTRODUCTION}

Steel-concrete composite columns have higher fire resistance than steel columns and it looks like the composite columns were developed to improve the fire resistance of steel columns. In practice, the most often used composite columns are: fully encased steel sections FES; partially encased steel sections PES and concrete filled tubular sections CFS. The columns with fully encased steel section may be treated in the same way as the reinforced concrete columns.

The concrete covers the steel section and protects it from intensive heating, i.e. acts like insulation to the steel section. In case of partially encased steel sections, the flanges of the steel section are directly exposed to fire and the effect of concrete as a "heat shield" is less. In case of concrete filled tubular sections the steel section is directly exposed to high temperatures while the concrete core remains cold and behaves as 'heat sink'. In such case stresses are redistributed to the relatively cool concrete core and the fire resistance is much higher than in case of steel columns without concrete core.

The load-bearing capacity of the column cross section can be determined from the interaction curve "bending moment-axial force". At elevated temperatures the stress-strain characteristics of concrete and steel become non-linear and deteriorate rapidly (EN 1994-1-2). This effect directly reflects on the reduction of the axial force and the bending moment that could be accepted by the column cross section, respectively the interaction curve of the column cross section is reduced.

In this study four different types of columns were analyzed, three of which were steel concrete composite columns with different cross sections (fully encased steel sections FES, partially encased steel sections PES and concrete filled tubular sections CFS), while the fourth one was a reinforced concrete column which had been taken for comparison, so as to draw the necessary conclusions for the advantage of the steel concrete composite columns over the reinforced concrete columns of the same size and the same initial loads. The "bending moment-axial force" interaction curves for all four types of columns were constructed as function of the time period of standard fire exposure and conclusions about the fire resistance of the columns were drawn out. For that purpose the computer program SAFIR, based on the simplified method recommended in Eurocode 4, part 1-2, was used. 


\section{M-N INTERACTION CURVE FOR COMPOSITE COLUMN CROSS SECTION}

In case when the axial force and the bending moment act simultaneously on the column cross section, the load-bearing capacity of the column can be defined from the "bending moment-axial force" interaction curve which presents the relationship between the design value of the plastic resistance to axial compression of the total cross-section $N_{p l, R d}$ and the design value of the bending moment resistance $M_{p l, R d}$, Figure 1 (EN 1994-1). The plastic resistance to compression $N_{\mathrm{pl}, \mathrm{Rd}}$ of a composite cross-section should be calculated by adding the plastic resistances of its components:

$$
N_{\mathrm{pl}, \mathrm{Rd}}=A_{a} f_{\mathrm{yd}}+0,85 A_{\mathrm{c}} f_{\mathrm{cd}}+A_{\mathrm{s}} f_{\mathrm{sd}}
$$

where $A_{a}, A_{s}, A_{c}$ are cross-sectional areas of structural steel section, reinforcement and concrete

$f_{y d}, f_{s d}, f_{c d}$ are design values of the yield strength of structural steel, reinforcing steel and the cylinder compressive strength of concrete

Equation (1) is used for totally encased and partially encased steel sections. For concrete filled sections the coefficient 0,85 may be replaced by 1,0 . The simplified $\mathrm{M}-\mathrm{N}$ interaction curve is constructed with 4 characteristic points: A, B, C and D (Figure 1).

Point $\mathrm{A}$ is defined with the design value of the plastic resistance of the composite section to compressive normal force $N_{\mathrm{pl}, \mathrm{Rd}}$, while the bending moment is zero (eccetricity e=0).

Point B is defined with the design value of the plastic resistance moment of the composite

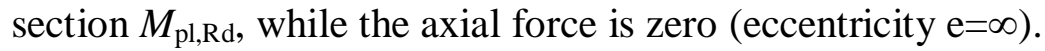

Point $\mathrm{C}$ is defined with the design value of the resistance of the concrete to compressive normal force $N_{\mathrm{pm}, \mathrm{Rd}},=0.85 A_{c} f_{c d}$ (for fully or partially encased steel sections) or $N_{\mathrm{pm}, \mathrm{Rd}},=A_{c} f_{c d}$ (for concrete filled tubular steel sections), while the bending moment is equal to $M_{\mathrm{pl}, \mathrm{Rd}}$.

Point D is defined with the maximum design value of the resistance moment $M_{\max , \mathrm{Rd}}$ in the presence of a compressive normal force $0.5 N_{\mathrm{pm}, \mathrm{Rd}}$.

The design value of the compressive normal force $N_{\mathrm{Ed}}$ corresponds to the design value of the plastic resistance moment of the composite section taking into account the compressive normal force $M_{\mathrm{pl}, \mathrm{N}, \mathrm{Rd}}$.
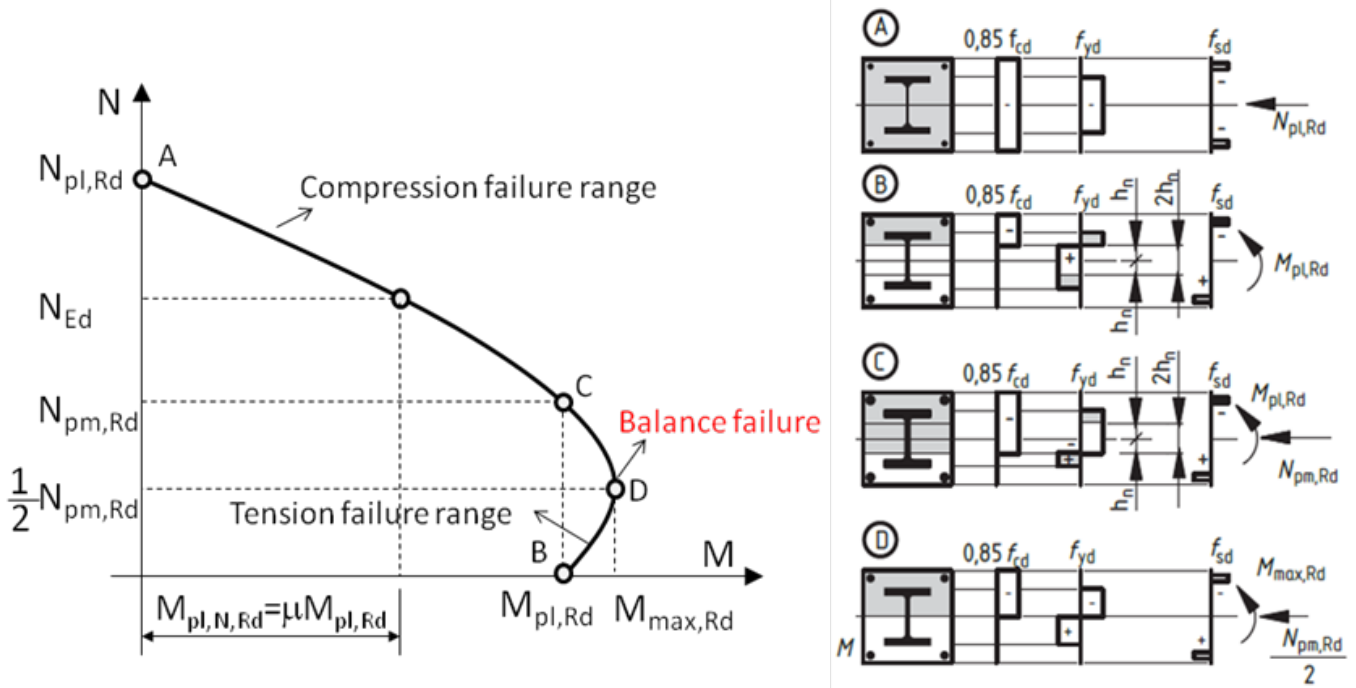

Fig. 1 Simplified interaction curve for composite column and corresponding stress distribution

\section{M-N INTERACTION CURVES FOR COMPOSITE COLUMNS IN CASE OF FIRE}

The stress-strain characteristics of concrete and steel become non-linear at elevated temperatures and deteriorate rapidly. This effect directly reflects on the reduction of the axial force and the bending moment that could be accepted by the columns, respectively the interaction curves of the columns cross sections are reduced. Construction of the M-N interaction curves for defined fire model and defined time of fire exposure is possible only if the temperature distribution in the cross section of the column is known. One of the options for solving this problem is the Finite Element 
Method (FEM). In this case the column has to be discretized into a number of elements and the cross section of the column has to be discretized into a number of smaller segments, sub-slices. The same finite element mesh has to be used for the nonlinear and transient thermal analysis and for the construction of M-N interaction curves (Adlinge, 2013, Cvetkovska et al., 2013, SAFIR, 2014).

Once the cross section of the column is discretized into a number of finite elements, sub-slices, (Figure 2) and the time dependent temperature field is defined, the corresponding curvature $\varphi$ for plastic resistance of the cross section and the number of steps for increasing the curvature up to the maximal $\varphi$ are assigned.

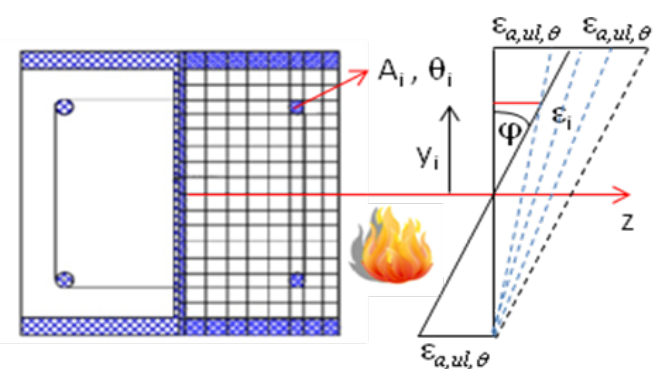

Fig. 2 Discretization of the column cross section into sub-slices and corresponding strains of the elements for the strong axis " $\mathrm{z}$ "

The equations (2), (3) and (4) define the axial force and the bending moment about the strong axis " $z$ " and weak axis " $y$ " for current temperature distribution of the composite column cross section.

$$
\begin{gathered}
N=\int_{A} \sigma(\theta) d A=\int_{y, z} \sigma(\theta) d y d z=\sum \sigma\left(\theta_{i}\right) \Delta y_{i} \Delta z_{i} \\
M_{z}=\int_{A} \sigma(\theta) y d A=\int_{y, z} \sigma(\theta) y d y d z=\sum \sigma\left(\theta_{i}\right) y_{i} \Delta y_{i} \Delta z_{i} \\
M_{y}=\int_{A} \sigma(\theta) z d A=\int_{y, z} \sigma(\theta) z d y d z=\sum \sigma\left(\theta_{i}\right) z_{i} \Delta y_{i} \Delta z_{i}
\end{gathered}
$$

According to Eurocode 4 part 1-2, the simplified procedure for construction the M-N interaction curves of composite columns at ambient temperatures can be used even for the fire exposed columns. In this case the design value of the plastic resistance to axial compression is given by:

$$
N_{f i, p l, R d}=\sum_{\mathrm{j}}\left(\mathrm{A}_{\mathrm{a}, \theta} \mathrm{f}_{\mathrm{ay}, \theta}\right) / \gamma_{\mathrm{M}, \mathrm{fi}, \mathrm{a}}+\sum_{\mathrm{k}}\left(\mathrm{A}_{\mathrm{s}, \theta} \mathrm{f}_{\mathrm{sy}, \theta}\right) / \gamma_{\mathrm{M}, \mathrm{fi}, \mathrm{s}}+\sum_{\mathrm{m}}\left(\mathrm{A}_{\mathrm{c}, \theta} \mathrm{f}_{\mathrm{c}, \theta}\right) / \gamma_{\mathrm{M}, \mathrm{fi}, \mathrm{c}}
$$

where $A_{i, \theta}$ is the area of each element (of the cross-section with defined temperature $\theta$ ),

$f_{a y, \theta}$ is the effective yield strength of structural steel at temperature $\theta$,

$f_{s y, \theta}$ is the effective yield strength of reinforcing steel at temperature $\theta$,

$f_{c, \theta}$ is the characteristic value for the compressive cylinder strength of concrete at temperature $\theta$,

$\gamma_{M, f i}$ are the partial factors for the strength of the corresponding materials in the fire situation.

For mechanical properties of steel and concrete, the recommended values of the partial factors for the fire situation are: $\gamma_{M, f i, a}=\gamma_{M, f i, c}=\gamma_{M, f i, s}=1,0$.

\subsection{M-N interaction curves of different types of composite columns}

The above described procedure is a part of the computer program SAFIR. This program was used for defining the temperature fields in the four different types of cross sections (Figure 3) exposed to standard fire ISO 834 from all four sides and only the heating phase was treated. The cross sections of the composite columns are: PES - partially encased steel profile HE 300A with an additional reinforcement $4 \varnothing 18$; CFS - concrete field tubular section with additional reinforcement $4 \varnothing 18$, FES 
- fully encased steel section HE 260A profile and RC- reinforced concrete section 40x40cm, reinforced with $8 \varnothing 25$, for comparison. In this case the $\mathrm{RC}$ section was treated as composite section and the simplified procedure for the $\mathrm{M}-\mathrm{N}$ diagrams, recommended in Eurocode 4 part 1-2, was used.

The criterion for dimensioning the columns was the design value of the plastic resistance to axial compression and for all four cross sections the value is close to $5500 \mathrm{KN}$. From the aspect of the heat transfer and the temperature distribution in the cross section of the columns, the dimensions of the three types of composite sections are almost the same, and only the RC cross section has bigger dimensions.

Thermal and mechanical properties of the steel, the concrete and the reinforcement were adopted according to the recommendations given in Eurocode 4, part 1-2.
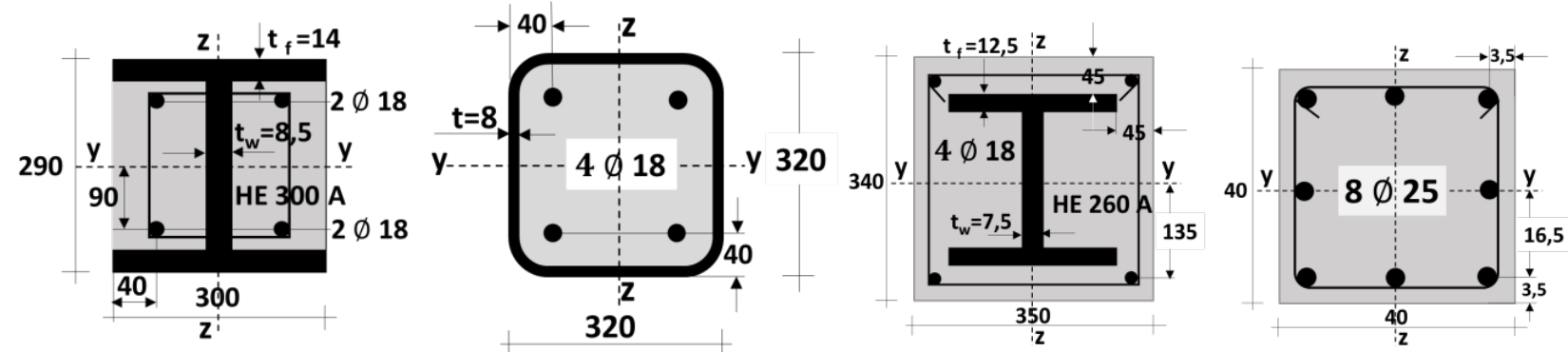

Fig. 3 Cross section geometry of the columns: PES - partially encased steel profile; CFS - concrete filled hollow section; FES - fully encased steel section and RC- reinforced concrete section

High temperatures caused by fire action reduce considerably the mechanical properties of the constitutive materials, consequently the axial force and biaxial bending moment bearing capacities of the columns are reduced, resulting in changes of the $\mathrm{M}-\mathrm{N}$ interaction diagrams. The "bending moment-axial force" interaction curves for all four types of columns were constructed as function of the time period of standard fire exposure according to the simplified procedure recommended in EN 1994-1-2 and are presented on Figures 4-6. The curves are different in case of bending moment about the strong axis and about the weak axis.
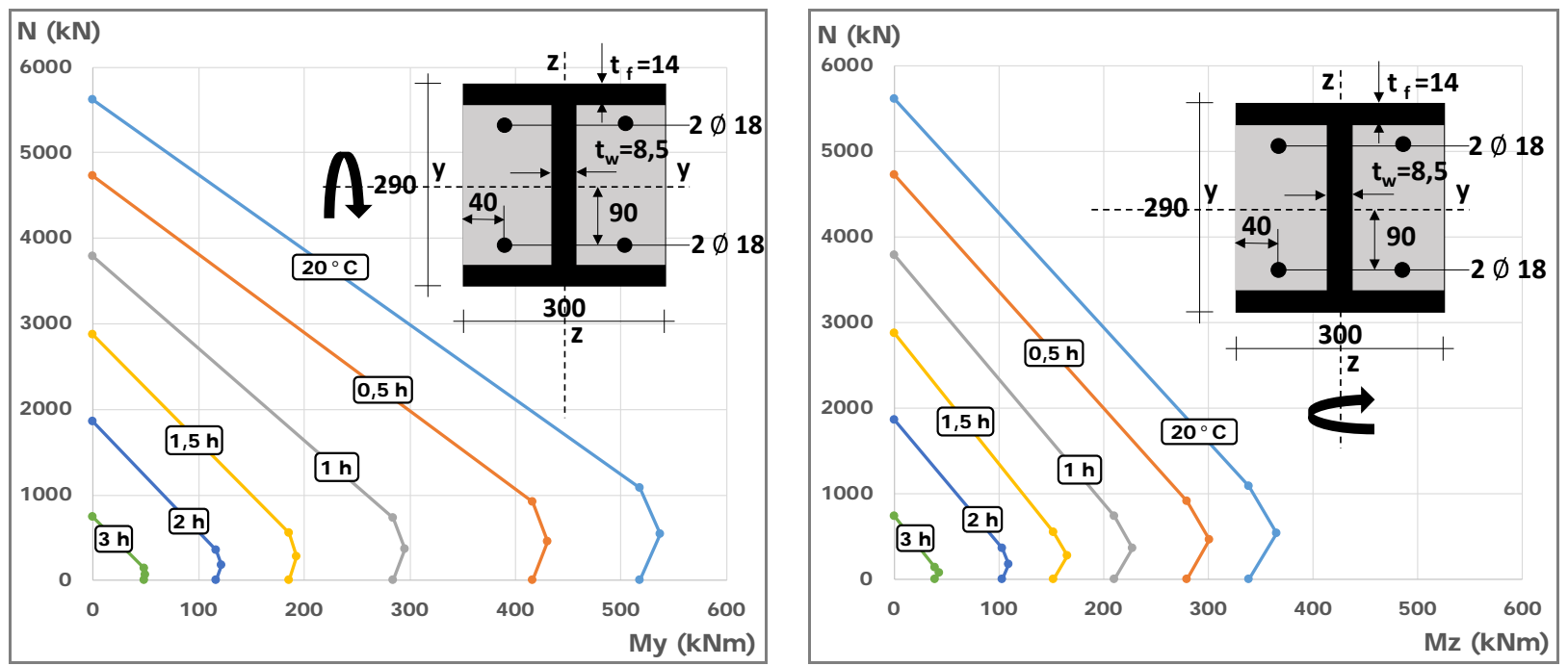

Fig. 4 M-N Interaction curves for bending moments about the strong and the weak axis of the PESpartially encased steel section, at different moments of fire exposure

From the previous figures we can see a significant reduction in the bearing capacity of the analyzed types of cross sections, caused by high temperatures during the fire action. Nevertheless, the loss of bearing capacity of the cross sections is not the same for all types of composite sections (Caldas et al., 2010, Fenollosa et al., 2013, Kuranovas et al., 2010). 

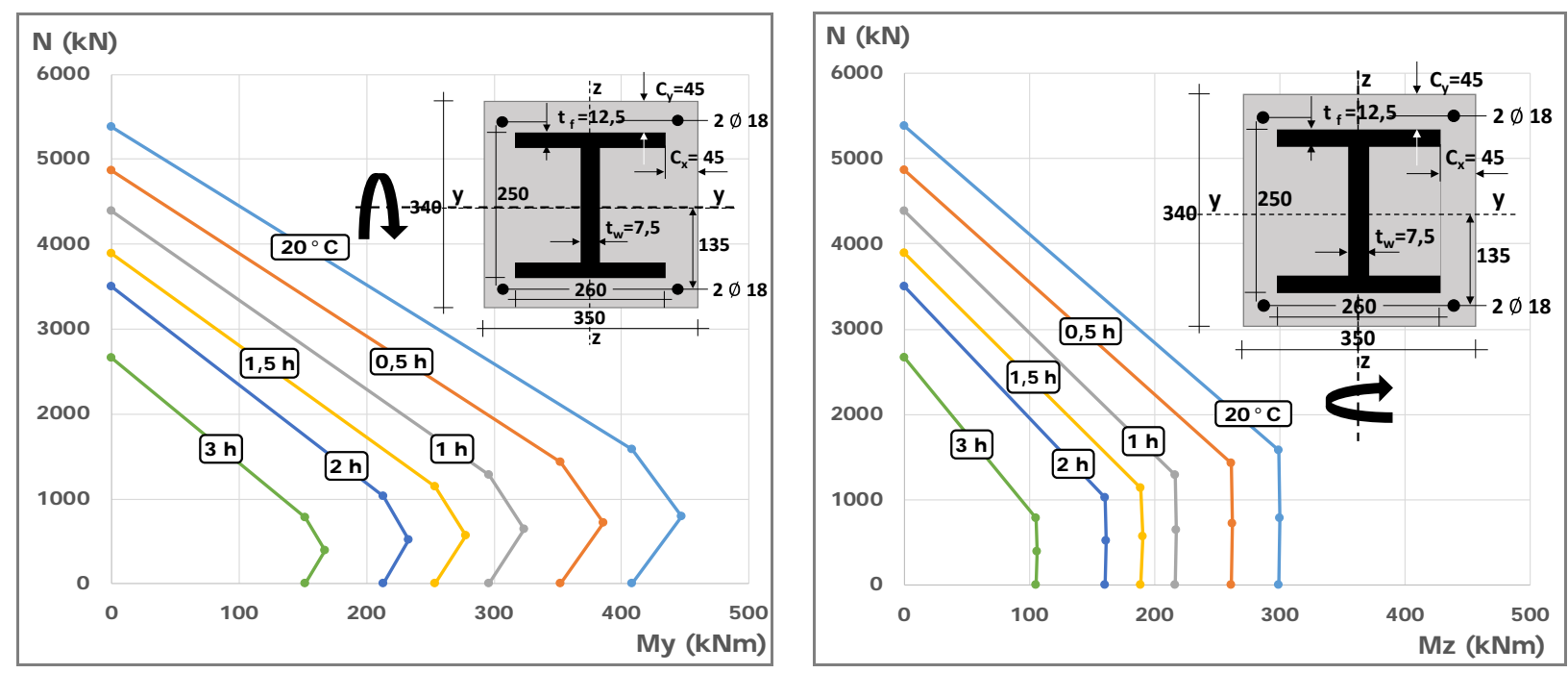

Fig. 5 M-N Interaction curves for bending moments about the strong and the weak axis of the FESfully encased steel section, at different moments of fire exposure
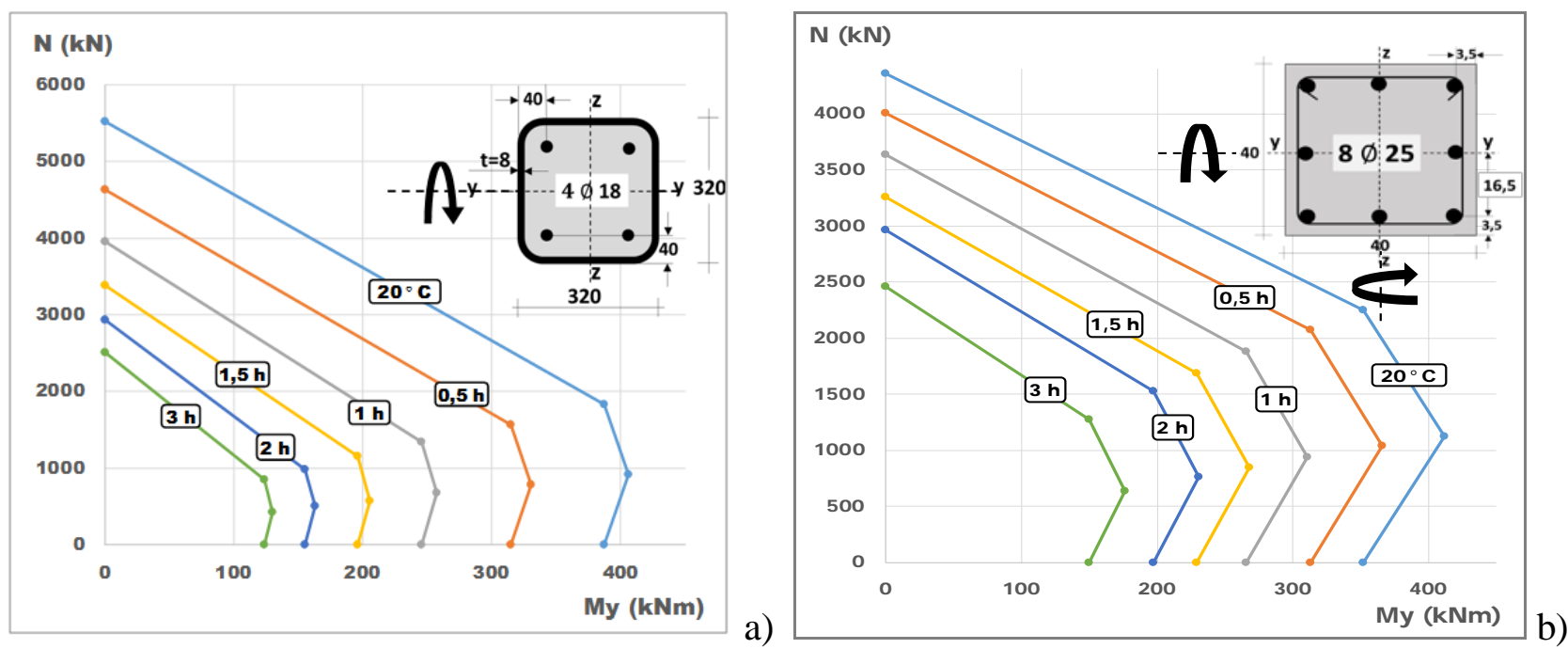

Fig. 6 M-N Interaction curves of: a) CFS-concrete filled hollow section, b) reinforced concrete cross section, at different moments of fire exposure

At ambient temperature, for the same dimensions of the cross section, the partially encased steel sections have the highest ultimate strength because the steel profile participates with high percent of the total area of the cross section. For these four types of sections, the lowest initial bearing capacity has the reinforced concrete section, where reinforcement takes $1 \%$ of the section.

In case of fire, highest fire resistance has the fully encased section (Figure 5) while the partially encased section and the concrete filled hollow section have lower fire resistance (Figure 4 and 6a). The steel profiles significantly increase the initial bearing capacity of the partially encased sections and the concrete filled hollow sections, but, because of the peripheral position of the steel it is heated to high temperatures in relatively short time period and the reduction of the mechanical properties of steel is caused, which results in lower fire resistance.

The steel profile of the totally encased section is in the interior of the section and it is protected by the concrete that has a low thermal conductivity, which provides the steel to stay cooler for a longer period of time and keep its mechanical properties which provides higher fire resistance.

Additional disadvantage of the partially encased section, in terms of fire resistance, is the proportional participation of the steel section which is higher than the one in the concrete hollow section; therefore, the partially encased section has higher ultimate strength for service conditions. 


\section{CONCLUSIONS}

The rise of temperature in the composite column cross sections, as a result of fire action, decreases the bearing capacity of the cross sections for axial compression force and biaxial bending. The reduction in the bearing capacity depends on the type of the cross section, the heating time, fire scenario etc. The highest loss of the $\mathrm{M}-\mathrm{N}$ bearing capacity is in the cross sections where the steel profile is directly exposed to heating, as for PES-partially encased sections. In sections, where the steel profile is protected with a concrete lining (FES section) there is a minimal reduction in the M$\mathrm{N}$ bearing capacity. Concrete, which is characterized by low thermal conductivity, prevents rapid penetration of the temperature into the steel element and the reinforcement and provides better behavior of the column. For the same reason the reinforced concrete column has highest fire resistance and lowest reduction of the bearing capacity.

The lowest decrease of the M-N bearing capacity in case of heating is observed in the FES composite column cross section (Figure 5). The reduction of the bearing capacity is almost linear.

As a result of the position in the CFS-concrete filled tubular cross section, the steel profile is directly exposed to the fire action, consequently high temperatures are reached from the very beginning of the heating process and there is a significant reduction in the material properties of the steel. For that reason there is a considerable reduction in the M-N interaction curves in the first hour of the fire action. With further heating the temperature slowly penetrates into the concrete core and this effect results with slow decrease in the remaining M-N bearing capacity of the column.

The difference in loss of the M-N bearing capacity of the FES and CFS cross sections, in some heating intervals, wasn't big. The biggest value of $9 \%$ is after one hour of fire exposure and decreased with further heating. After three hours of heating it drops down to 3.5\%. This effect definitely has to be taken into account when choosing the right type of column cross section, especially having to know the considerable advantages of the CFS columns over the PES columns in construction without formwork, simpler connections to the girder elements etc. Also, the possibility for additional fire protection on the perimeter of the CFS columns, gives them a considerable advantage over the remaining types of columns.

The reduction in the M-N bearing capacity of the PES section in relation to the other two analyzed sections is $14 \%$ after the first hour of heating, 32\% after two hours of heating and $36.3 \%$ after three hours of heating. These data indicate that their application in structures that could be exposed to fires is not justified without the additional protection (insulation) of the section.

\section{REFERENCES}

Adlinge S.S., Gupta A.K. 2013. Study of Ultimate Load Capacity of Concrete Encased steel Columns using Finite Element Method, International Journal of Advance Research, IJOAR .org

Caldas R.B., Sousa J.B.M., Fakury R.H. 2010. Interaction diagrams for design of concrete-field tubular columns under fire, Proceedings of SDSS-Stability and Durability of Steel Structures, Rio de Janeiro, Brazil

Cvetkovska M., Milanovic M., Jovanoska M., Cifliganec C. 2013. Parametric analysis of fire resistance of centrically loaded composite steel-concrete columns, $15^{\text {th }}$ International Symposium of Macedonian Association of Structural Engineers, Ohrid, Makedonija

EN 1992-1-2: Eurocode 2. 2004. Design of concrete structures - Part 1-2: General rules. Structural fire design

EN 1994-1-1: Eurocode 4. 2004. Design of composite steel and concrete structures - Part 1-1: General rules and rules for buildings

EN 1994-1-2: Eurocode 4. 2005. Design of composite steel and concrete structures - Part 1-2: General rules. Structural fire design

Fenollosa E., Cabrera I. 2013. Analysis of composite section columns under axial compression and biaxial bending moments, Structures and Architecture: Concepts, Applications and Challenges, ISBN 978-0415-66195-9, Taylor \& Fransis Group, London

Kuranovas A., Goode D., Kazimieras A. 2010. Load - bearing capacity of concrete - filled steel columns, Journal of Civil Engineering and Management, Taylor \& Francis, pp. 21-33

SAFIR. 2014. Computer program, University of Liege, Belgium 